\title{
Multidrug-Resistant Bacterial Isolates Recovered from Herbal Medicinal Products Sold in Nairobi, Kenya
}

\author{
Richard Korir, ${ }^{a, b}$ Omu Anzala, ${ }^{b}$ Walter Jaoko, ${ }^{b}$ Christine Bii, ${ }^{a}$ Lucia Keter ${ }^{a}$ \\ ${ }^{a}$ Kenya Medical Research Institute, Nairobi, Kenya; ${ }^{b}$ University of Nairobi, School of Medicine, Nairobi, Kenya. \\ Correspondence to Richard Korir (richkori@yahoo.com).
}

\begin{abstract}
Background: Medicinal herbs have been reported to be contaminated with microorganisms indigenous to the environment. These microbes become a threat when they harbour drug-resistant traits.

Objective: The aim of this study was to evaluate phenotypic and genotypic drug-resistant traits of bacteria isolated from herbal medicinal products in Nairobi, Kenya.

Methods: We employed an exploratory as well as laboratory-based experimental design. Herbal products were purchased from markets and transported to Kenya Medical Research Institute laboratories for processing and analysis. Microbial contamination and antibiotic susceptibility were determined following standard methods. Antibiotic-resistant genes were determined using polymerase chain reaction. Data were coded and analysed accordingly.

Results: We collected 138 samples of herbal products in the form of liquids, powders, capsules, creams/lotions, and syrups. In total, 117 samples (84.8\%) were contaminated with bacteria and 61 (44.2\%) were contaminated with fungi. Bacillus, Klebsiella, Proteus, Staphylococcus, Streptomyces, Escherichia, Enterobacter, Serratia, Yersinia, Morganella, Citrobacter, Erwinia, and Shigella were the bacterial genera identified. Most of the isolated bacteria were generally sensitive to the panel of antibiotics tested, although a few (35 [36.5\%]) were resistant; more than half of these were resistant to more than 1 of the antibiotic agents we tested.

Discussion: We found an association between phenotypic and genotypic drug resistance among the drug-resistant bacteria. This study makes it evident that herbal medicinal products sold in Nairobi are contaminated with drug-resistant bacteria.

Conclusions: The results show that herbal medicinal products are a potential source of dissemination of multidrugresistant bacteria. There is an urgent need for specific education programmes, policies, and regulations that address herbal products' safety to prevent the possibility of these pathogens being involved in deadly invasive infections.
\end{abstract}

\section{INTRODUCTION}

\footnotetext{
A ntibiotic-resistant bacteria have been a source of an ever increasing therapeutic challenge. ${ }^{1}$ Continued mismanagement of antibiotics and the resulting selective pressure have contributed to the emergence of multidrug-resistant bacteria; this has been regarded as an inevitable genetic response to antimicrobial therapy. ${ }^{2}$ Drug-resistant infectious microbes have become an important public health concern that warrants organisations in public and private sectors worldwide working together. ${ }^{3,4}$ Aside from the public health threat, the search for newer microbial-sensitive treatments to overcome resistant microbes is usually very expensive and contributes to the higher costs of health care, which is attributed to longer hospital stays. ${ }^{4}$
}

Microbial resistance to antimicrobial agents is usually mediated through gene coding for resistance. The resistant genes are either chromosomal (intrinsic) or plasmid encoded (extrinsic). Plasmids are selfreplicating extra chromosomal DNA molecules found in Gram-negative and Gram-positive bacteria as well as in some fungi (yeast and moulds). ${ }^{5}$

Determination of antibiotic-resistant genes through the use of polymerase chain reaction (PCR) techniques provides insights on genetic information relating to resistance to 1 or more antibiotics. The genetic information may also reflect the extent or amount of the multidrug resistance. ${ }^{6}$ Bacteria which are resistant to antibiotic agents may develop anywhere, especially in a confined environment previously contaminated with drug-sensitive bacteria. One such environment 
can be in herbal medicinal products (HMPs), and HMPs have been previously implicated as a pool for such contamination. ${ }^{7,8}$

The use of HMPs as a form of complementary medicine is becoming increasingly popular in both developing and developed countries. ${ }^{7}$ About $70 \%$ to $80 \%$ of the world's population, particularly in the developing world, has been shown to depend on herbal drug regimens for their primary health care. ${ }^{9}$ As the pros and cons of HMPs are pondered, it is important to monitor and ascertain their pureness, as HMPs contaminated with microbes, especially drug-resistant microbes, may pose important health, medical, and economic implications. ${ }^{7}$

Monitoring of HMPs will help to identify microbial contamination, provide information on the rate of antimicrobial resistance, and devise mechanisms to slow down the rate of emergence of drug-resistant strains from HMPs. ${ }^{10}$ In the present study, we evaluated selected HMPs from Nairobi, Kenya, for the presence of contaminating microorganisms. These microorganisms were later subjected to susceptibility studies to establish their resistance profiles. The DNA for phenotypic-resistant isolates were extracted and used to determine genotypic resistance using specific primers coding for antibiotic-resistant genes.

\section{MATERIALS AND METHODS}

\section{Study Site and Design}

The study was undertaken in Nairobi, the capital and largest city in Kenya. Nairobi has several herbal clinics, especially in densely populated areas. However, HMPs are also sold in health food stores, pharmacies/chemists, supermarkets, local retailers, and hawkers, among other outlets. This study employed an exploratory as well as laboratory-based experimental design.

\section{Sample Collection}

We collected HMPs from different herbal vendors across Nairobi County. The study sample included 138 different
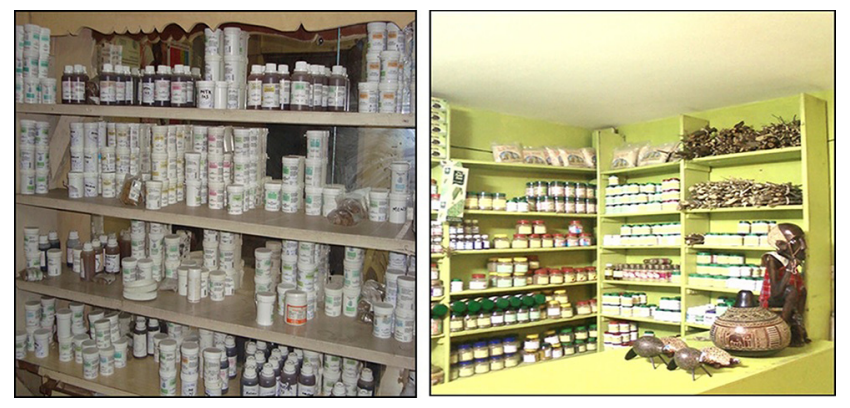

Herbal Products Displayed on Shelves. A, Herbal products sold in herbal chemist or health food stores. B, Herbal products sold in herbal clinic.
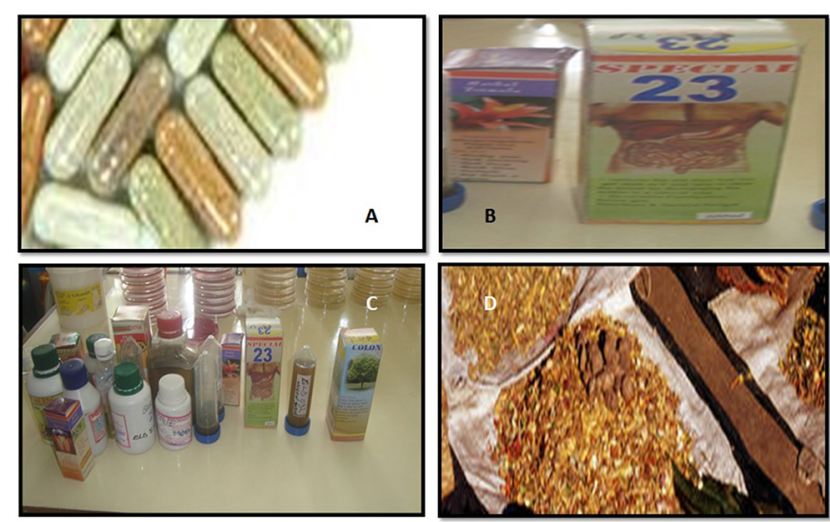

Formulations of Herbal Products. A, Capsules. B, Liquid (concoctions). C, Syrups and concoctions. D, Powdered roots and stem barks.

HMPs in different preparations, which included liquids, powders, capsules, creams/lotions, and syrups.

\section{Isolation and Identification of Contaminating Bacteria}

Each HMP was serially diluted and plated in triplicate on selective, differential, and general purpose media for bacteria growth. HMPs were incubated at $37^{\circ} \mathrm{C}$ for 12 to 18 hours. The ensuing colonies were further purified, isolated, and characterised using standard methods. ${ }^{11}$

\section{Susceptibility Testing of the Bacterial Isolates}

Briefly, the following antimicrobial discs were placed onto Mueller-Hinton agar plates seeded with the bacteria strains: piperacillin, ciprofloxacin, norfloxacin, cefotaxime, gentamicin, sulphamethoxazole/trimethoprim, chloramphenicol, and ceftazidime. The plates were incubated overnight for 12 to 18 hours, and any microorganism that showed resistance $^{12}$ to any of the antibiotics was isolated for further resistance DNA isolation studies. After isolation, the bacteria were stocked and stored in a negative $40^{\circ} \mathrm{C}$ deep freezer. ${ }^{13}$

\section{DNA Extraction, PCR, and Gel Electrophoresis}

The bacteria were retrieved from the freezer, thawed, and cultured in brain heart infusion broth at $37^{\circ} \mathrm{C}$ overnight. Total DNA were extracted from $5 \mathrm{~mL}$ of a broth culture grown overnight. After incubation, bacterial cells were harvested by centrifugation at 3,000 rpm (radius $7.20 \mathrm{~cm}$ ) for $10 \mathrm{~min}$ utes; the cell pellets were suspended in phosphate-buffered saline with $100 \mu \mathrm{g}$ of lysostaphin per millilitre and incubated at $37^{\circ} \mathrm{C}$ for 30 minutes. The phenol/chloroform extraction method was used for nucleic acid extraction, and the DNA was precipitated in $1 \mathrm{~mL}$ of $70 \%$ ethanol. The DNA precipitate was dissolved in $50 \mu \mathrm{l}$ of TE buffer (10 mM Tris- 
$\mathrm{Cl}, 1 \mathrm{mM}$ EDTA; $\mathrm{pH} 8.0$ ) and stored at negative $20^{\circ} \mathrm{C}$ until processing. ${ }^{13}$

The PCR amplification was performed in a $25 \mu \mathrm{l}$ reaction mixture $(2.5 \mathrm{~mL}$ of $10 \times$ reaction buffer without $\mathrm{MgCl} 2$; $200 \mu \mathrm{M}$ of each deoxynucleoside triphosphate, $2 \mathrm{mM} \mathrm{MgCl}$; $2.5 \mathrm{pmol}$ of each primer and approximately $2-4 \mu \mathrm{l}$ of template DNA) and brought up to a $25 \mu$ final volume with sterile DNA/RNA-free distilled water. To reduce the formation of nonspecific extension products, a 'hot-start' protocol was adapted. The PCR reactions were hot-started for 5 minutes at $95^{\circ} \mathrm{C}$ and placed on ice, and $2 \mu \mathrm{l}$ of Taq polymerase was added. Reaction mixtures were subjected to 30 PCR cycles $\left(95^{\circ} \mathrm{C}\right.$ for 2 minutes, then 1 minute at $54^{\circ} \mathrm{C}$, and $1 \mathrm{mi}-$ nute at $72^{\circ} \mathrm{C}$ ). A final elongation step of 7 minutes at $72^{\circ} \mathrm{C}$ was applied in a thermal cycler. ${ }^{13}$

Among the drug-resistant isolates, the following genes were investigated:

- The aacA-aphD gene coding for gentamicin resistance, with 227 base pairs. The primers are aacA-aphD: F-TAA TCC AAG AGC AAT AAG GGC and aacA-aphD: R-GCC ACA CTA TCA TAA CCA CTA.

- The $b l a_{C M Y}$ gene, which has 205 base pairs and is responsible for fourth-generation cephalosporin (cefepime, ceftazidime) resistance. Its primers are $b l a_{C M Y}$ : F-GAC AGC CTC TTT CTC CAC and bla ${ }_{C M Y}:$ R-TGG AAC GAA GGC TAC GTA.

- The bla $a_{C T X-M}$ single gene coding for cefotaxime and piperacillin resistance, which has 499 base pairs. Its primers are CTX-M1: F3-GAC GAT GTC ACT GGC TGA GC and CTXM1: R2-AGC CGC CGA CGC TAA TAC A.

- The gyra is a single gene that codes for norfloxacin and ciprofloxacin resistance and has 574 base pairs. Its primers are gyrA: Fl-ATG TCA GAC AAT CAA CAA CAA GC and gyrA: R3-ACA TTC TTG CTT CTG TAT AAC GC.

- The SulA gene that codes for sulphamethoxazole/trimethoprim resistance and has 360 base pairs. Its primers are SulA: F-AC TGC CAC AAG CCG TAA and SulA: R-GTC CGC CTC AGC AAT ATC. ${ }^{14}$

The DNA products were loaded on an agarose gel, and gel electrophoresis was performed to separate the mixture of DNA pellets. The DNA bands (products) were visualised using ultraviolet transmission light and were photographed alongside the controls and molecular weight markers. ${ }^{13}$ We then identified the DNA bands in reference to the controls to determine the associated genes. This information was used to correlate the phenotypic and genotypic characteristics of the targeted drug-resistant bacteria.

\section{RESULTS}

We collected and analysed 138 samples of HMPs. These samples included 106 powders $(76.8 \%), 18$ liquids $(13.0 \%)$,
8 syrups $(5.8 \%), 4$ creams/lotions $(2.9 \%)$, and 2 capsules $(1.4 \%)$. Seventy-four of the samples $(53.6 \%)$ came from street vendors/hawkers, $34(24.6 \%)$ from herbal clinics, $19(13.8 \%)$ from supermarkets/shops, 7 (5.1\%) from manufacturers/wholesalers, and 2 each $(1.4 \%)$ from chemists and health food stores.

Bacteria isolated from the collected HMPs were grouped into 13 genera: Bacillus, Klebsiella, Proteus, Staphylococcus, Streptomyces, Escherichia, Enterobacter, Serratia, Yersinia, Morganella, Citrobacter, Erwinia, and Shigella. The genera and species of the bacteria isolated from HMPs are shown in the Table.

For this study, we tested $96(100.0 \%)$ isolates of bacteria for susceptibility to the commonly used antibiotics. Most of the isolated bacteria (61 [63.5\%]) were generally sensitive to the panel of antibiotics. Thirty-one $(32.3 \%)$ bacterial isolates were resistant to ceftazidime; $33(34.4 \%)$ were resistant to cefotaxime; $2(2.1 \%)$ were resistant to gentamicin; $5(5.2 \%)$ were resistant to chloramphenicol; $1(1.0 \%)$ was resistant to piperacillin; and $2(2.1 \%)$ each were resistant to norfloxacin and ciprofloxacin, respectively.

The isolated bacteria were resistant to either 1 or more than 1 antibiotic. The following isolates were resistant to only 1 antibiotic: Morganella morganii (MM2), resistant to chloramphenicol; Enterobacter cloacae (EC3), resistant to ceftazidime; and Proteus penneri (PP20), resistant to cefotaxime. Four isolates were resistant to 3 antibiotics: Citrobacter diversus (CD1), resistant to gentamicin, cefotaxime, and norfloxacin; M morganii (MMl), resistant to sulphamethoxazole/trimethoprim, chloramphenicol, and cefotaxime; Enterobacter aerogenes (EA2), resistant to ceftazidime, cefotaxime, and piperacillin; and Klebsiella pneumoniae (KP2), resistant to sulphamethoxazole/trimethoprim, ceftazidime, and cefotaxime.

Two isolates exhibited resistance to 4 antibiotics: $C$ diversus (CD2), resistant to sulphamethoxazole/trimethoprim, chloramphenicol, norfloxacin, and ciprofloxacin; and E cloacae (EC5), resistant to sulphamethoxazole/trimethoprim, ceftazidime, cefotaxime, and norfloxacin. Twenty-six isolates were resistant to 2 antibiotics. Most of these isolates (22 [62.9\%]) were resistant to both ceftazidime and cefotaxime.

Bacterial DNA extraction was performed and was later amplified independently with reverse and forward primers in a single reaction in order to determine antibiotic-resistant genes among the phenotypic-resistant isolates. The bacteria were $C$ diversus (CD1 and $\mathrm{CD} 2$ ), $E$ aerogenes (EA2), E cloacae (EC2, 3, 4, 5, 8, 9, and 10), Erwinia chrysanthemi (ERC1), $K$ pneumoniae (KP2), M morganii (MM1 and 2), P penneri (PP4, 8, 9, 10, 11, 12, 13, 17, 18, 20, 21, and 22), Serratia marcescens (SMl and 2), Serratia rubidaea (SR4, 6, and 7), and Yersinia enterocolitica (YE3, 6, 7, and 8).

Except for 2 isolates, all the bacteria found to be resistant to the drugs were found to contain drug-resistant genes. There was an association between the phenotypic and 
TABLE. Genus and Specific Epithets of the Isolated Bacteria

\begin{tabular}{llrr}
\hline Genus & Organism(s) & Gram Reaction & Frequency (\%) \\
\hline Citrobacter & C diversus & Gram - & $3(100.0)$ \\
Enterobacter & E aerogens, E cloacae & Gram - & $22(100.0)$ \\
Streptomyces & S spp. & Gram + & $74(100.0)$ \\
Bacillus & B anthracoides, B spp. & Gram + & $64(100.0)$ \\
Erwinia & Echrysanthemi & Gram - & $1(100.0)$ \\
Escherichia & E coli & Gram - & $7(100.0)$ \\
Morganella & M morganii & Gram - & $2(100.0)$ \\
Klebsiella & K pneumoniae & Gram - & $4(100.0)$ \\
Proteus & P penneri & Gram - & $25(100.0)$ \\
Serratia & S fonticola, S marcescens, S rubidaea & Gram - & $14(100.0)$ \\
Shigella & S sonnei & Gram - & $1(100.0)$ \\
Staphylococcus & Saureus & Gram + & $5(100.0)$ \\
Yersinia & Yenterocolitica & Gram - & $11(100.0)$ \\
Total & & & $233(100.0)$ \\
\hline
\end{tabular}

Abbreviations: Gram -, gram negative; Gram +, gram positive.

genotypic drug resistance among the drug-resistant isolates. All the isolates that were phenotypic resistant to cefotaxime and ceftazidime contained the $b l a_{C T X-M}$ gene and the $b l a_{C M Y}$ gene.

Figure 1 shows DNA fragments for isolates that were resistant to cefotaxime; the bla $_{C T X-M}$ gene has 499 base pairs. Figure 2 shows DNA fragments for isolates that had genes coding for ceftazidime resistance; the $b l_{C M Y}$ gene has 205 base pairs.

\section{DISCUSSION}

HMPs designed for chemotherapeutic and pharmacological benefits should be effective against the targeted medical condition. Several factors could compromise this goal, including contamination with pathogenic and nonpathogenic microorganisms. ${ }^{15}$ Apart from possible microbial degradation of the active constituents contained in the HMPs, the presence of contaminating microorganisms could constitute a source of infection and a serious health risk to consumers, who were probably already overwhelmed by the serious medical conditions for which the HMPs were initially indicated. ${ }^{16}$ Drug-resistant traits in products that are consumed can lead to serious health conditions which do not respond to antibiotic agents.
In this study, soil bacteria formed the bulk of the isolates found. These bacteria were Streptomyces species (74 [53.6\%]) and Bacillus anthracoides (64 [46.4\%]), which indicate environmental contamination. According to a study done by Grierson, ${ }^{17} B$ anthracoides is pathogenic to guinea pigs and mice under experimental conditions, and it would appear to occupy a position between the virulent Bacillus anthracis and the nonpathogenic members of the group of aerobic sporing bacilli (e.g., Bacillus subtilis, Bacillus mesentericus). When people who are sick are exposed to $B$ anthracoides through consumption of contaminated HMPs, this could pose a serious health risk.

Escherichia coli were isolated in liquid HMP formulations, which include concoctions, decoctions, and infusions. Generally all the liquids were dissolved in water; hence the water for dissolution might have contained $E$ coli. $E$ coli is an indication of faecal contamination and is associated with gastroenteritis.

The most important bacteria we isolated in terms of potential human diseases were K pneumoniae, Staphylococcus aureus, Proteus species, Shigella sonnei, and E coli (among other coliforms). These results concur with a similar study by Frazier and Westhoff, ${ }^{18}$ who isolated bacteria of clinical importance such as Bacillus species, Salmonella species, and $E$ coli from herbal products, although the current study did 


\section{FIGURE 1. Bacterial Isolates with bla $a_{C T X-M}$ Gene Coding for Cefotaxime Resistance with 499 Base Pairs}

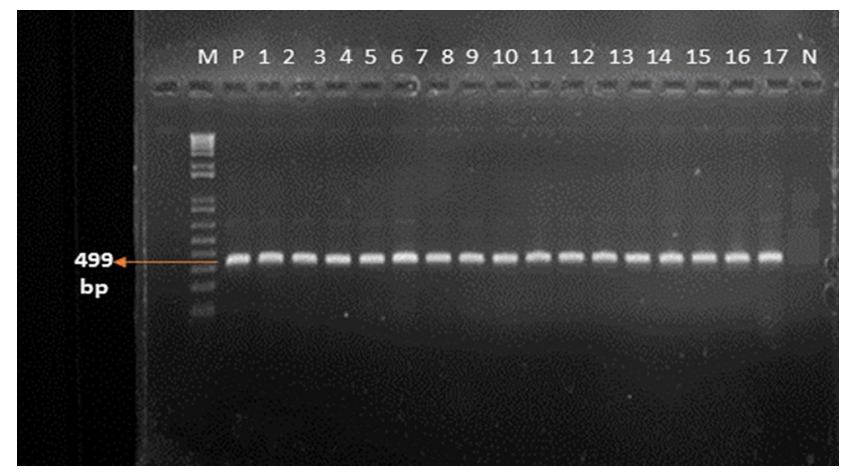

Lane $M$ is a molecular marker with different bands denoting different molecular weights: each band stands for 150 base pairs. Lane $P$ is the positive control; Lane $N$ is the negative control; and Lanes 1-17 show bacterial isolates containing the bla CTX-M gene. The blaCTX-M gene has 499 base pairs

\section{FIGURE 2. Bacterial Isolates with bla $\mathrm{CMY}_{\mathrm{Y}}$ Gene Coding} for Ceftazidime Resistance with 205 Base Pairs

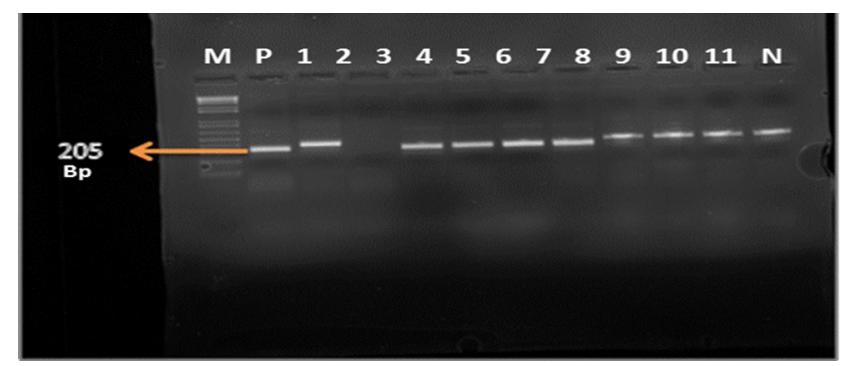

Lane $M$ is a molecular marker with different bands denoting different molecular weights: each band stands for 50 base pairs. Lane $P$ is the positive control; Lane $\mathrm{N}$ is the negative control; and Lanes 1-11 show bacterial isolates containing the bla CMY gene. The bla $_{C M Y}$ gene has 205 base pairs

not find any species of Salmonella. Shukla and colleagues, ${ }^{19}$ in a similar study, reported a high recovery rate of these suspected infectious bacteria from indigenous orally consumed herbal medications. Danladi and colleagues ${ }^{20}$ found similar results in their study on herbal preparations. However, these other studies did not determine drug susceptibility of the isolated bacteria.
The majority of the bacterial isolates found in this study (61 [63.5\%]) were sensitive to the antibiotics tested. These results concur with a study done by Alwakeel on microbial contaminants of herbal medicine, where he found that most $(75 \%)$ of the bacteria isolated were sensitive to the antibiotics, ${ }^{21}$ but did not determine the presence of drugresistant genes.

Testing bacterial pathogens for their responses to chemotherapeutic agents is common practice in clinical and food microbiology. ${ }^{22}$ In our study, $36.5 \%$ of the isolated bacteria were resistant to the panel of antibiotics we tested. Other studies have observed a higher level of resistance $(46.2 \%$ to $51.7 \%$ ) to the commonly used antibiotics. ${ }^{22,23}$ Angulo and colleagues $^{24}$ alleged that the ability of bacteria to evolve mechanisms to resist attack by antimicrobials was recognised soon after the widespread deployment of the first antibiotics. DeWaal and colleagues ${ }^{25}$ have also suggested that resistance is an inevitable consequence of antibiotic use; the more antibiotics are used, the more bacteria will develop resistance to them.

All the bacteria we found to be drug-resistant, except for $2(5.7 \%)$ isolates, were found to contain resistant genes. The antibiotic-resistant bacterial isolates were resistant to either 1 or more than 1 of the antibiotics tested and were also found to contain drug-resistant genes. There was a direct association between phenotypic resistance and genotypic resistance.

Antibiotics are used to treat bacterial infections. They may be used as a short- or long-term treatment, depending on whether the problem is acute or chronic. A study by Ash and colleagues ${ }^{26}$ found that bacteria with intrinsic resistance to antibiotics are found in nature. Such organisms may acquire additional resistant genes from other bacteria introduced into soil or water, and the resident bacteria may be the reservoir or source of the widespread drug-resistant organisms found in many environments. In bacteria, antimicrobial resistance is facilitated by the ability to quickly adapt to new environments and to replicate very quickly. From this comes the aptitude to mutate the DNA acquired from other drug-resistant bacteria. ${ }^{4}$

The acquisition of resistance to drugs may be due to chromosomal mutations or mobile genetic elements like plasmids that are often capable of transfer from one strain of organism to another, even across the species barrier. Plasmid transfer within and across species is further enhanced through the activities of transposons, which are mobile genetic elements that can confer resistance determinants. ${ }^{5}$ The ability of transposons to integrate into either conjugative plasmids or into an organism's chromosomes enhances the transferability of a given determinant of resistance. ${ }^{25}$

This process is a natural phenomenon exacerbated by the abuse, overuse, and misuse of antimicrobials in the treatment of human illness and in animal husbandry, aquaculture, and agriculture. ${ }^{2}$ When drug-resistant organisms are 
present in medicaments, such as HMPs, they could behave as opportunist pathogens and initiate an infection, particularly in immune-compromised patients. They can also lead to transfer of antibiotic-resistant traits to hitherto drugsensitive microorganisms that cohabit within the consumers of the contaminated products.

Given the increasing rate of development of resistant bacteria strains, the main challenge is to slow the rate at which resistance develops and spreads. To do this, physicians, pharmacists, researchers, and consumers alike need to be more aware of the selective pressures that drive these bacteria to decrease their susceptibility. ${ }^{2}$ These selective pressures include the abuse, overuse, and misuse of antimicrobials in therapy; improper manufacturing and mishandling of HMPs; ${ }^{2,5}$ and numerous other socioeconomic factors that govern the development of multidrug-resistant bacteria strains. ${ }^{26}$ In such circumstances, a collective and concerted effort towards preventing the development of resistant bacteria strains through rational antimicrobial use policy, right practices, and intensive research leading to novel and alternative drug therapies would help check the emergence of multidrug-resistant bacteria strains.

\section{CONCLUSION AND RECOMMENDATIONS}

The results of the present work show that HMPs were contaminated with both pathogenic and nonpathogenic bacteria. Of concern was the multidrug resistance found among the isolated bacteria, since only 3 isolates were resistant to only 1 drug, while 32 isolates were resistant to more than 1 antibiotic. All the drug-resistant bacteria harboured drugresistant genes. The high rate of strains with multidrug resistance that were isolated from these herbal preparations may indicate widespread antibiotic resistance among microorganisms from different sources. It is therefore important that quality assurance is built into the whole process of manufacturing HMPs. Thus, there is a need for constant monitoring and control of the microbial standards of herbal medicines available on the market. Further studies should sequence bacteria that are found to have genotypic resistance in order to determine their relatedness. Mobileresistant genes should be determined, because bacteria that share the same environment can transfer mobile genes to antibiotic-sensitive bacteria through plasmids and transposons.

Acknowledgements: We are very grateful to the National Commission for Science, Technology and Innovation (NACOSTI) for funding this work. We would also like to sincerely acknowledge the heads of the Kenya Medical Research Institute and the University of Nairobi for providing an enabling environment for this work to be done.

\section{REFERENCES}

1. Sheikh AR, Afsheen A, Sadia K, Abdul W. Plasmid borne antibiotic resistance factors among indigenous Klebsiella. Pak J Bot. 2003;35(2):243-248.
Available from: http://mww. pakbs.org/pibot/PDFs/35(2)/PJB35(2)243.pdf. Accessed February 28, 2017.

2. Oleghe PO, Odimegwu DC, Udofia E, Esimone CO. Multi-drug-resistant bacteria isolates recovered from herbal medicinal preparations in a Southern Nigerian setting. J Rural Trop Public Health. $2011 ; 10(1): 70-75$. Available from: http://jitph.jcu.edu.au/vol/JRTPH_Vol10_p70-75_Oleghe.pdf. Accessed February 28, 2017

3. Agwu E, Ohihion AA, Agba Ml, et al. Incidence of Streptococcus pneumoniae infections among patients attending tuberculosis clinics in Ekpoma, Nigeria. Shiraz E Med J. 2006;7(1):1-8. Available from: http://emedicali.com/?page= article\&article_id=20395. Accessed February 28, 2017.

4. Ujam NT, Oli AM, lkegbunam MN, et al. Antimicrobial resistance evaluation of organisms isolated from liquid herbal products manufactured and marketed in South Eastern Nigeria. Br J Pharm Res. 2013;3(4):548-562. Available from: http://www.sciencedomain.org/abstract/1390. Accessed February 28, 2017

5. Lexchin J. Promoting resistance? Essential Drugs Monitor. 2000;28-29:11. Available from: http://apps.who.int/medicinedocs/en/d/Js2248e/9.html. Accessed February 28, 2017.

6. Karlin S, Brendel V. Chance and statistical significance in protein and DNA sequence analysis. Science. 1992;257(5066):39-40. Medline

7. Esimone $\mathrm{CO}$, Oleghe PO, Ibezim EC, Okeh CO, Iroha IR. Susceptibility-resistance profile of micro-organisms isolated from herbal medicine products sold in Nigeria. Afr J Biotechnol. 2007;6(24):2766-2775. CrossRef

8. Keter L, Too R, Mwikwabe N, et al. Bacteria contaminants and their antibiotic sensitivity from selected herbal medicinal products from Eldoret and Mombasa, Kenya. Am J Microbiol. 2016;7(1):18-28. CrossRef

9. World Health Organization (WHO). WHO Guidelines for Assessing Quality of Herbal Medicines With Reference to Contaminants and Residues. Geneva: WHO Press; 2007. Available from: http://apps. who.int/medicinedocs/en/d/ Js14878e/. Accessed February 28, 2017.

10. Saper RB, Kales SN, Paquin J, et al. Heary metal content of ayurvedic herbal medicine products. JAMA. 2004;292(23):2868-2873. Medline

11. CowanSI,SteelKJ. CowanandSteel's Manualfortheldentification of MedicalBacteria. BarrowGI, Feltman RKA, eds. Cambridge:CambridgeUniversityPress; 1993.

12. Lalitha MK. Manual on Antimicrobial Susceptibility Testing. 7th ed. Delhi: Indian Association of Medical Microbiologists; 2004. Available from: http://documents. $\mathrm{mx} /$ documents/manual-on-antimicrobial-susceptibility-testing-dr-mk-lalitha.html. Accessed February 28, 2017.

13. Duran N, Ozer B, Duran GG, Onlen Y, Demir C. Antibiotic resistance genes and susceptibility patterns in staphylococci. Indian J Med Res. 2012;135(1):389-396. Medline

14. Liu $F, H u Y$, Wang $Q$, et al. Comparative genomic analysis of Mycobacterium tuberculosis clinical isolates. BMC Genomics. 2014;15(1):469. CrossRef. Medline.

15. Okunlola A, Adewoyin BA, Odeku OA. Evaluation of pharmaceutical and microbial qualities of some herbal medicinal products in Southwestern Nigeria. Trop J Pharm Res. 2007;6(1):661-670. CrossRef

16. Bowler PG, Duerden BI, Armstrong DG. Wound microbiology and associated approaches to wound management. Clin Microbiol Rev. 2001;14(2):244-269. CrossRef. Medline

17. Grierson AM. Bacillus anthracoides. A study of its biological characters and relationships and its pathogenic properties under experimental conditions. Journal of Hygiene. 1928;27(3):306-320. CrossRef. Medline

18. Frazier WC, Westhoff DC. Food Microbiology. 4th ed. New York: McGraw-Hill; 1988.

19. Shukla SK, Stemper ME, Ramaswamy SV, et al. Molecular characteristics of nosocomial and Native American community-associated methicillin-resistant Staphylococcus aureus clones from rural Wisconsin. J Clin Microbiol. 2004;42(8):3752-3757. CrossRef. Medline

20. Abba D, Inabo HI, Yakubu SE, Olonitola OS. Contamination of herbal medicinal products marketed in Kaduna metropolis with selected pathogenic bacteria. Afr J Tradit Complement Altern Med. 2008;6(1):70-77. Medline

21. Alwakeel SS. Microbial and heary metal contamination of herbal medicines. Res J Microbiol. 2008;3(12):683-691. CrossRef 
22. Adenike AO, Ogunshe T, Taiwo TK. In vitro phenotypic antibiotic resistance in bacterial flora of some indigenous orally consumed herbal medications in Nigeria. J Rural Trop Public Health. 2006;5(1):9-15. Available from: http://irtph.jcu.edu. au/vol/v05adenike1. pdf. Accessed February 28, 2017.

23. Adeleye IA, Okogi G, Ojo EO. Microbial contamination of herbal preparations in Lagos, Nigeria. J Health Popul Nutr. 2005;23(3):296-297. Medline

24. Angulo FJ, Nargund VN, Chiller TC. Evidence of an association between use of anti-microbial agents in food animals and anti-microbial resistance among bacteria isolated from humans and the human health consequences of such resistance. J VetMed B Infect Dis Vet Public Health. 2004;51 (8-9):374-379. CrossRef. Medline

25. DeWaal CS, Vaughn Grooters S. Antibiotic resistance in foodborne pathogens. Washington (DC): Center for Science in the Public Interest; 2013. Available from: https://cspinet.org/resource/antibiotic-resistance-foodborne-pathogens. Accessed February 28, 2017

26. Ash RJ, Mauck B, Morgan M. Antibiotic resistance of Gram-negative bacteria in rivers, United States. Emerg Infect Dis. 2002;8(7):713-716. CrossRef. Medline

\section{Peer Reviewed}

Competing Interests: None declared.

Received: 9 Jan 2017; Accepted: 10 Feb 2017

Cite this article as: Korir R, Anzala O, Jaoko W, Bii C, Keter L. Multidrug-Resistant Bacterial Isolates Recovered from Herbal Medicinal Products Sold in Nairobi, Kenya. East African Health Res J. 2017;1(1):40-46. https://doi.org/10.24248/EAHRJ-D17-00027

(C) Korir et al. This is an open-access article distributed under the terms of the Creative Commons Attribution License, which permits unrestricted use, distribution, and reproduction in any medium, provided the original author and source are properly cited. To view a copy of the license, visit http://creativecommons.org/licenses/by/3.0/. When linking to this article, please use the following permanent link: https://doi.org/ 10.24248/EAHRJ-D-17-00027 